few days after operation. The ligatures may be removed about the fifth or sixth day. A patient who has undergone this operation should be provided with a day and night nurse, and in hospitals they should have nothing to do with the dressing of other cases.

\section{ON \\ CHANGES IN THE STRUCTURE OF THE BONES CAUSED BY DISEASE OF THE BRAIN.}

BY T. S. CLOUSTON, M.D., MTDICAL STPERITTEXDEXTT OF THE CTMEERIAND AYD WESTIORELAYD ASYLLY.

Mr attention was arrested a short time ago, while making a post-mortem examination in the case of a wornan who had for many years laboured under partial hemiplegia, with aphasia and insanity, by the extreme softness and friability of the bones. The ribs could be broken quite easily between the finger and thumb, and could be cut through readily with an ordinary knife. The long bones were quite easily broken also, and most of them could be cut. In this case I did not examine at all into the chemical or structural changes that had taken place in the bone. The woman was sixty-two years of age. A short time afterwards I found the same condition of the bones in a woman of fifty, who had laboured under general paralysis for two years. On reading the recent shocking accidents to patients in asylums from fractures of the ribs and sternum, my attention was directed afresh to the state of the bones in general paralysis. It will have been observed by medical men that every patient in whom such injuries wore found after death had laboured under general paralysis. I have only had two deaths from that disease since those accidents have occurred, and in both I have carefully examined the state of the ribs.

M. B-, aged forty-six, had laboured under general paralysis for three year's. On testing the fifth rib, I found that when it was suspended by a piece of wire, one end of which was fixed at its sternal extremity, and the other at a distance of $3 \frac{3}{4}$ in. along the rib, and a graduated weight hung between those tro points, it broke with $9 \mathrm{lb} .12 \mathrm{oz}$. On applying the same test to the fifth rib of a healthy man who had died in the Carlisle Infirmary, it broke with a weight of $30 \mathrm{lb} .13 \mathrm{oz}$. The latter was just twice the size of the former (as tested by weighing equal lengths of both), and it bore a weight more than three times as much. I find the quantity of calcareous salts to be about 10 per cent. more in the general paralytic's rib. I have not yet had time to examine its microscopic structure. In the second case the strength of the ribs was, in proportion to their size, as great as the healthy rib.

The above observations are as yet very incomplete; but if the conclusion to which they point be true-namely, that in general paralysis there is a tendency in some cases to extreme brittleness of the bones,-it shows that in such cases extra care and special precaution should be taken, by those who have the charge of them in asylums, that no injury is done to them. It seems to me almost impossible that such injuries as those found in Nistri's case, in Hanwell Asylum, could have been caused by even a strong and merciless attendant, except the ribs and sternum had undergone some morbid change.

January, 1870.

Fatal Peritonitis induced by a Worm - At a late meeting of the Pathological Society of Dublin an interesting case was detailed of a worm causing death from perforation of the intestine. Two patients were admitted by Dr. Gordon suffering from a low kind of fever, with bronchitis. A short time after admission a lumbricoid norm was discharged through the mouth of each patient. Peritonitis, however, existed in one of the cases, and death took place within thirty-six hours. After death it was found that the intestine had been perforated by the worm, thereby causing the peritonitis from which the patient had died.

\section{A aftirtor}

OF THE PRACTICE OF

\section{MEDICINE AND SURGERY IN THE}

\author{
HOSPITALS OF LONDON.
}

Nulla autem est alia pro certo noscendi via, nisi quamplurimas et morborum et dissectionum historias, tum aliorum, tum proprias collectas habere, et inter se comparare.-Mongagni De Sed. et Caus. MTorb., lib. iv. Proœmium.

\section{GUY'S HOSPITA L. \\ MISCELLANEOUS CASES. \\ (Under the care of Dr. WILKs.)}

Temporary General Paralysis. - Dr. Wilks has recently directed special attention to an interesting case of paralysis, in which, in the course of two months, loss of motor power had extended from the lower to the upper limbs, and finally involved to a slight extent the muscles of deglutition. The patient, who was a middle-aged man, on admission into the hospital, was treated by good nourishment and rest. He is now rapidly recovering, and can move his legs. Dr. Wilks, in some clinical remarks, stated that this case required careful study: he could not tell what was the condition of the nervous tracts, as the temporary abeyance of their functions indicated that there could be no severe inflammatory or degenerative lesion. Temporary nervous deranoements of this kind might be accounted for by alterations in the vascular supply to certain regions of the brain and cord. Allusion was made by Dr. Wilks to a case of a boy whose carotid artery was tied by Mr. Birkett, and who, about half an hour after the operation, became hemiplegic, and remained in this condition for two days, when the paralysis passed off.

Paralysis in Epileptics.-In some clinical remariss upon a case of loss of motor power on the rioht side of a child having a history of epileptic fits, Dr. Wilks stated that permanent paralysis never followed uncomplicated epilepsy. Temporary weakness of one side of the body might follow epileptic convulsions, but when the loss of power persisted, it was generally due to some lesion of the hrain or its coverings. In the case then under his notice, the child had probably had hydrocephalus or meningitis in its infancy, and the permanent weakness on the right side was perhaps a result of the healing processes. A similar state of weakness in an arm or $1 \mathrm{eg}$ on one side of the body often remained permanent after hemiplegia from cerebral bæmorrhage, for which the patient generally undergoes a prolonged course of treatment without any relief. This muscular debility is due to the formation of a cicatrix in the brain, and to try to remove this would be as irrational as the attempt to cause absorption of a scar seated in the interument on the surface of a limb.

Treatment of Headache. - Dr. Wilks has recently administered hydrate of chloral to a man with Bright's disease, who complained of persistent and very severe headache, extending from the frontal region to the occiput. In this instance but very little if any relief was afforded. Here the pain in the head was probably due to diseased arteries. In cases of simple neuralgic headache, howerer, Dr. Willss believes that the hydrate acts efficaciously. Bromide of potassium is a very useful agent in some forms of cephalalgia, especially those in which there is thickening of the cerebral membranes or cranial bones. In these cases Dr. Wills believes that the remedy gives relief, not so much by virtue of its special action on the nervous system as by causing absorption-an action which the bromide of potassium, in common with the iodide, undoubtedly possesses.

\section{LONDON HOSPITAL}

(Mr. Micrden's Clinic, January, 1870.)

Arrowg cther cases is one of pain in bone; another of separation of the lower epiphssis of the femur; a third of separation of the epiphysis of the head of the femur; a 